\title{
Response to microsurgical anatomy of lumbosacral spinal roots
}

\author{
Safiye Çavdar ${ }^{1}$
}

Received: 27 March 2015 / Accepted: 19 May 2015 /Published online: 4 June 2015

(C) Springer-Verlag Wien 2015

Dear Editor,

We would like to thank d'Avella D. and Mingrino S. for their compliments to our recent manuscript entitled "morphological study of the spinal dorsal root entry zone" (by Kirazi Ö, Tatarli N, Güçlü B, Ceylan D, Ziyal İ, Keleș E, Çavdar S (2014) Acta Neurochir 156: 2351-2358).

We are sorry that we have overlooked d'Avella D, Mingrino S (1979) Microsurgical anatomy of lumbosacral spinal roots. J Neurosurg 51: 819-823.
The results of our study and the study by d'Avella D and Mingrino S. highly corresponds. Further, the two reports contribute to the understanding that the posterolateral sulcus does not exhibit a constant anatomical pattern, which can be clinically important.

We have submitted a paper on the connections of the dorsal rootlets, which is under review and will also highly contribute to the understanding and the importance of connections and variations of the dorsal rootlets and their clinical importance.

Safiye Çavdar

scavdar@ku.edu.tr

School of Medicine, Department of Anatomy, Koç University, 34450 Sariyer, Istanbul, Turkey 